\title{
TRIGGERING OF ERYTHROCYTE MEMBRANE BLEBBING BY CIPROFLOXACIN
}

\author{
KASHIF SHABIR ${ }^{\# 1}$, KASHIF JILANI**1, MOHANAD ZBIDAH ${ }^{2}$, AL-FARGA AMMAR $^{2}$, \\ MUHAMMAD RIAZ ${ }^{3}$, SHAIKH MUHAMMAD AMJAD ${ }^{4}$, ISMAT BIBI ${ }^{5}$, MUHAMMAD IRFAN ${ }^{1}$ \\ ASMA ASGHAR ${ }^{1}$ and MUHAMMAD AKBAR ${ }^{1}$
}

${ }^{1}$ Department of Biochemistry, University of Agriculture, Faisalabad, Pakistan ${ }^{2}$ Department of Biochemistry, Faculty of Science, University of Jeddah, Saudi Arabia

${ }^{3}$ Department of Allied Health Sciences, University of Sargodha, Sargodha

${ }^{4}$ King Salman Center of Kidney Diseases, Riyadh, Saudi Arabia

${ }^{5}$ Department of Chemistry, The Islamia University of Bahawalpur, Pakistan

\begin{abstract}
An extensively used fluoroquinolone antibiotic ciprofloxacin shows broad-spectrum antibacterial activity against both gram-positive and gram-negative strains. It works mainly by the inhibition of DNA gyrase and topoisomerase IV which results in impaired DNA replication leading towards microbial cell death. Eryptosis is an alternative term used for suicidal erythrocyte death. In the current study, the eryptotic effect of ciprofloxacin was investigated by exposing erythrocytes for 48 hours to the different concentrations $(45-90 \mu \mathrm{M})$ of ciprofloxacin. The experimental work related to the investigation of eryptosis was done by cell size measurement and confirmation of calcium role in membrane blebbing. As a possible mechanism of eryptosis, oxidative stress induced by ciprofloxacin was determined by catalase, glutathione peroxidase, and superoxide dismutase activities measurement. Similarly, the necrotic effect of ciprofloxacin was also illustrated by hemolysis measurement. Results of our study revealed that the therapeutical doses of ciprofloxacin may induce oxidative stress by a significant decrease in superoxide dismutase, catalase and glutathione peroxidase activities as well as induce eryptosis, featured by erythrocytes membrane blebbing and hemolysis.
\end{abstract}

Keywords: oxidative stress, calcium, cell size

Ciprofloxacin is a fluoroquinolone carboxylic acid derivative with antibacterial activity against both gram-positive and gram-negative bacteria. It can be administered by intravenous infusion or oral route (1). Ciprofloxacin prescribed against several infectious diseases including cystic fibrosis associated with Pseudomonas and Bacillus related anthrax (2). It is found that the ciprofloxacin administration may contribute to some adverse effects including heart-related abnormalities (3) and tendon affecting disorders (4).

The alternative name of programmed cell death of mitochondria and nucleus deficient erythrocytes is eryptosis, mainly characterized by shrinkage, membrane blebbing (5) and cell membrane scrambling which may lead to phosphatidylserine translocation (6). Splenic macrophages recognize, engulf and degrade phosphatidylserine exposed erythrocytes (7). Oxidative stress is among the events that are responsible for eryptosis (5). Free radical generation activates non-specific cation channels that may results in high intracellular calcium activity (8). High cytosolic calcium level causes the $\mathrm{Ca}^{+2}$ sensitive $\mathrm{K}^{+}$channels activation which may lead to cell shrinkage due to $\mathrm{KCl}$ and water loss (5). Breakdown of cytoskeleton and phosphatidylserine exposure on erythrocyte's cell membrane is also the dependent on calcium influx $(9,10)$. In case of un compensation, triggered eryptosis may lead to anemia that contributes to pathophysiology of several clinical disorders (11). Different xenobiotic compounds were investigated and found to have strong eryptotic activity with indicated concentrations by adopting different mechanisms (12).

The present work was mainly done to explore the oxidative stress induction and blebbing effect on erythrocyte membrane after treatment with therapeutical doses of ciprofloxacin.

\footnotetext{
* Corresponding author: e-mail: kashif.jillani@uaf.edu.pk

${ }^{\#}$ Contributed equally and thus shares first authorship
} 


\section{Material and method}

For experimental work, screened blood samples were collected from different blood banks of Faisalabad city. The work has been conducted after approval from the directorate of graduate studies and IBC, University of Agriculture Faisalabad, Pakistan.

Leukocyte depleted cells were prepared by following the protocol explained by Pastor et al., 1998 (13). Isolated erythrocytes were stored in separate microcentrifuge tubes. In vitro incubations of erythrocytes were performed at a hematocrit of $0.4 \%$ in ringer solution ( $\mathrm{pH}$ 7.4) that contain (in $\mathrm{mM}$ ) $\mathrm{MgSO}_{4} 1, \mathrm{NaCl} 125, \mathrm{KCl} 5$, glucose 5, $\mathrm{CaCl}_{2} 1, \mathrm{~N}-2-$ hydroxyethylpiperazine-N-2-ethanesulfonic acid (HEPES) 32 at $37^{\circ} \mathrm{C}$ for $48 \mathrm{~h}$ (14). Isolated erythrocytes were treated with ciprofloxacin (SigmaAldrich, USA) at higher concentrations than the indicated therapeutical doses $(15,16)$.

\section{Oxidative stress measurement}

To determine the oxidative stress in ciprofloxacin exposed erythrocytes, antioxidant enzme's (superoxide dismutase, catalase, glutathione peroxidase) assays were performed.

\section{Superoxide dismutase}

Superoxide dismutase's activity was measured by following the protocol of Giannopolitis and Ries, 1977 (17). The reaction solution contained methionine $0.222 \mathrm{~g}$ in $15 \mathrm{~mL} \mathrm{H}_{2} \mathrm{O}$, NBT $0.015 \mathrm{~g}$ in $17.5 \mathrm{~mL}$ $\mathrm{H}_{2} \mathrm{O}$, Triton-X $0.0375 \mathrm{~mL}$ in $17.5 \mathrm{~mL} \mathrm{H}_{2} \mathrm{O}$, riboflavin $0.0132 \mathrm{~g}$ in $17.5 \mathrm{~mL} \mathrm{H}_{2} \mathrm{O}$ and buffer 0.2 M.

\section{Catalase}

Catalase activity was determined by using the protocol of Ullah et al. (2018) (18). Phosphate buffer (pH7) $50 \mathrm{mM}, \mathrm{H}_{2} \mathrm{O}_{2} 5.9 \mathrm{nM}$ and enzyme extract $0.1 \mathrm{~mL}$ were added in reaction mixture and absorbance was read at $240 \mathrm{~nm}$.

\section{Glutathione peroxidase}

Phosphate buffer (pH 5) $50 \mathrm{mM}$, guaiacol 20 $\mathrm{mM}, \mathrm{H}_{2} \mathrm{O}_{2} 40 \mathrm{mM}$ and enzyme extract $0.1 \mathrm{~mL}$ were added in the reaction mixture by following the protocol of Ullah et al. (2018) (18) and activity was measured at $470 \mathrm{~nm}$ after every $20 \mathrm{Sec}$.

\section{Cell size measurement}

Mean cell volume (MCV) was measured to determine the cell size of control and treated erythrocytes. MCV was checked by using an automated hematology analyzer (19).

\section{Confirmation of $\mathrm{Ca}^{+2}$ role}

To confirm the role of calcium in the stimulation of membrane blebbing, erythrocytes were treated with 45-90 $\mu \mathrm{M}$ ciprofloxacin in $\mathrm{Ca}^{2+}$ free ringer solution. In $\mathrm{Ca}^{2+}$ free ringer, $1 \mathrm{mM} \mathrm{CaCl}_{2}$ was replaced by $1 \mathrm{mM}$ glycol-bis(2-aminoethylether)N,N,N',N'-tetraacetic acid (10). The inhibition of blebbing was confirmed by MCV measurement.

\section{Hemolysis measurement}

After incubation, samples were centrifuged (3 $\mathrm{min}$ at $400 \mathrm{~g}$ at room temperature) and the supernatant was collected to determine hemolysis. Hemoglobin concentration was measured at $405 \mathrm{~nm}$ (20). The absorption of the supernatant of erythrocytes lysed in d. $\mathrm{H}_{2} \mathrm{O}$ was defined as $100 \%$ hemolysis (21).

\section{Statistical analysis}

All data are expressed as arithmetic means \pm SEM. Statistical analysis was made by using ANOVA with Tukey's test as post-test (14). For statistical analysis of the data, software GraphPad InStat was used.

\section{RESULTS AND DISCUSSION}

The prime objective of the study was to find out the oxidative and membrane blebbing effect of ciprofloxacin on erythrocytes. For this purpose, antioxidant's enzymatic activities, erythrocyte's size determination, confirmation of calcium role and hemolytic activity were performed. As mentioned earlier, the ciprofloxacin concentrations used to treat isolated erythrocytes were above the indicated ones $(15,16)$. Figure 1 is illustrating that the 48-hour exposure of erythrocytes to ciprofloxacin (45-90 $\mu \mathrm{M})$ leads to mild and highly significant decrease in activities of superoxide dismutase at $45 \mu \mathrm{M}$ and 90 $\mu \mathrm{M}$ respectively. Previously it was reported that ciprofloxacin exposure significantly lowers the activity of superoxide dismutase in treated cells which is the indication of oxidative stress (22). Superoxide dismutase catalyzes the dismutation of $\mathrm{O}_{2}$ free radicals which on accumulation results in lowering of superoxide dismutase's level and mitochondrial functions (23). Figure 2 is illustrating the catalase activities in human erythrocytes after 48hour ciprofloxacin (45-90 $\mu \mathrm{M})$ exposure. Results depict similar trends like superoxide dismutase activities as mild and highly significant decrease in enzyme's activity noticed at 45 and $90 \mu \mathrm{M}$ of ciprofloxacin respectively, which may be due to the generation of reactive oxygen species. Previous find- 


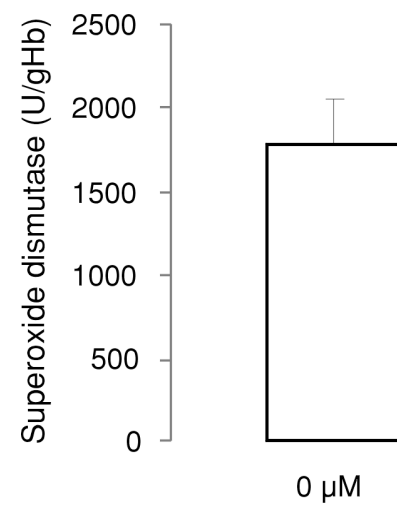

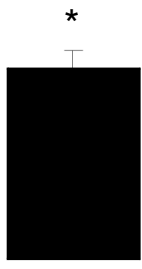

$45 \mu \mathrm{M}$

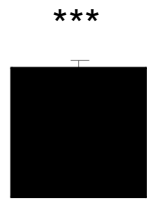

$90 \mu \mathrm{M}$

\section{Ciprofloxacin}

Figure 1. Effects of Ciprofloxacin on superoxide dismutase activities (U/g Hb) in erythrocytes. Arithmetic means \pm SEM ( $\mathrm{n}=15)$ of the erythrocytes exposed for 48 hours to ringer solution without (white bar) or with (black bars) in (45-90 $\mathrm{uM}$ ) ciprofloxacin. Y-axis bars show the standard error mean $(\mathrm{SEM}){ }^{*}, * * *(\mathrm{p}<0.05),(\mathrm{p}<0.0001)$ indicate a significant difference from the absence of ciprofloxacin $($ ANOVA)
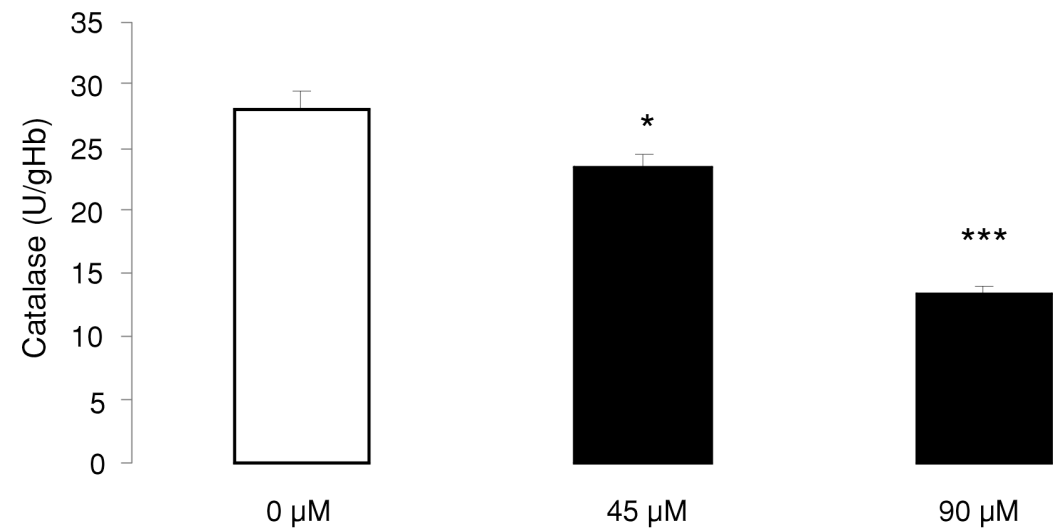

\section{Ciprofloxacin}

Figure 2. Effect of Ciprofloxacin on catalase activities $(\mathrm{U} / \mathrm{g} \mathrm{Hb})$ in erythrocytes. Arithmetic means \pm SEM $(\mathrm{n}=15)$ of the means in erythrocytes unprotected for 48 hours to ringer solution without (white bar) or with (black bars) in (45-90 $\mu \mathrm{M})$ ciprofloxacin. Y-axis bars show the standard error mean $(\mathrm{SEM}) . *{ }^{*} * *(\mathrm{p}<0.05),(\mathrm{p}<0.001)$ indicate significant difference from the corresponding control value (ANOVA)

ings related to catalase activity revealed that the increased level of reactive oxygen may result in the lowering of catalase level (24). Furthermore, hydrogen peroxide accumulation may end with the lowering of catalase activities. Catalase is a major antioxidant enzyme that is involved in the decomposition of $\mathrm{H}_{2} \mathrm{O}_{2}(25)$ and showed a protective effect against oxidants in cells during their overproduction (26). Figure 3 is demonstrating the activities of enzyme glutathione peroxidase resulted after 48-hour treatment of erythrocytes with 45 and $90 \mu \mathrm{M}$ of ciprofloxacin. A mild $(45 \mu \mathrm{M})$ and highly $(90 \mu \mathrm{M})$ significant decrease activity of the enzyme was observed in the experiment that may be due to generation of reactive oxygen species. In a relevant study, it is described that the reduction in glutathione's activity may be due to the induction of oxidative stress (27). Activities of glutathione peroxidase in the mitochondrial cell membrane prevent the accumulation of oxidized lipids and decompose hydrogen peroxide into water (28). The reduction in the activities of superoxide dismutase, catalase and glutathione peroxidase is confirming our hypothesis about the production of oxidative stress at 45-90 $\mu \mathrm{M}$ of ciprofloxacin. 
Figure 4 illustrated that 48-hour exposure of erythrocytes with ciprofloxacin (45 and $90 \mu \mathrm{M}$ ) resulted in an apparent but significant increase in mean cell volume of erythrocytes at both concentrations that may be due to membrane blebbing. Erythrocytes membrane blebbing i.e. swelling or protrusions is a potential marker of eryptosis (29).

For the confirmation of calcium role in the stimulation of eryptosis by ciprofloxacin, calcium was depleted from the ringer solution. Figure 5 depicting the cell size measurement of erythrocytes after 48 -hour exposure to ciprofloxacin $(45 \mu \mathrm{M})$ in the calcium-free environment. It is reported that the non-selective cation channels are triggered by oxidative stress and leads to high cytosolic concentration and subsequent events of eryptosis (10). In this experiment, no significant membrane blebbing was observed in erythrocytes incubated with ciprofloxacin $(45 \mu \mathrm{M})$ in calcium-free ringer that may be due to the unavailability of calcium. Furthermore, a

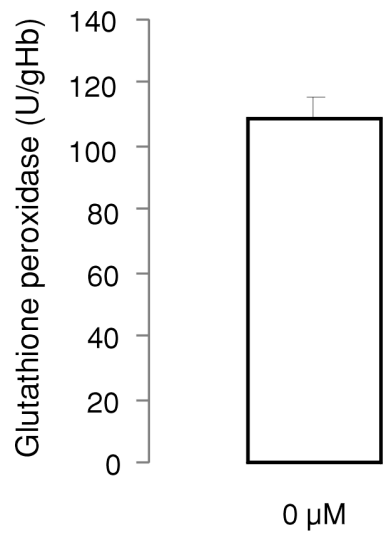

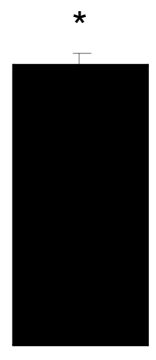

$45 \mu \mathrm{M}$

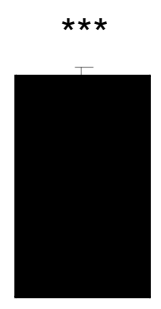

$90 \mu \mathrm{M}$

\section{Ciprofloxacin}

Figure 3. Effect of Ciprofloxacin on glutathione peroxidase activities (U/g Hb) in erythrocytes. Arithmetic means \pm SEM $(\mathrm{n}=15)$ of the glutathione peroxidase in treated erythrocytes exposed for 48 hours to ringer solution without (white bar) or with (black bars) in (45-90 $\mu \mathrm{M})$ ciprofloxacin. $* * * *(\mathrm{p}<0.05),(\mathrm{p}<0.0001)$ indicate significant difference from the absence of ciprofloxacin (ANOVA)
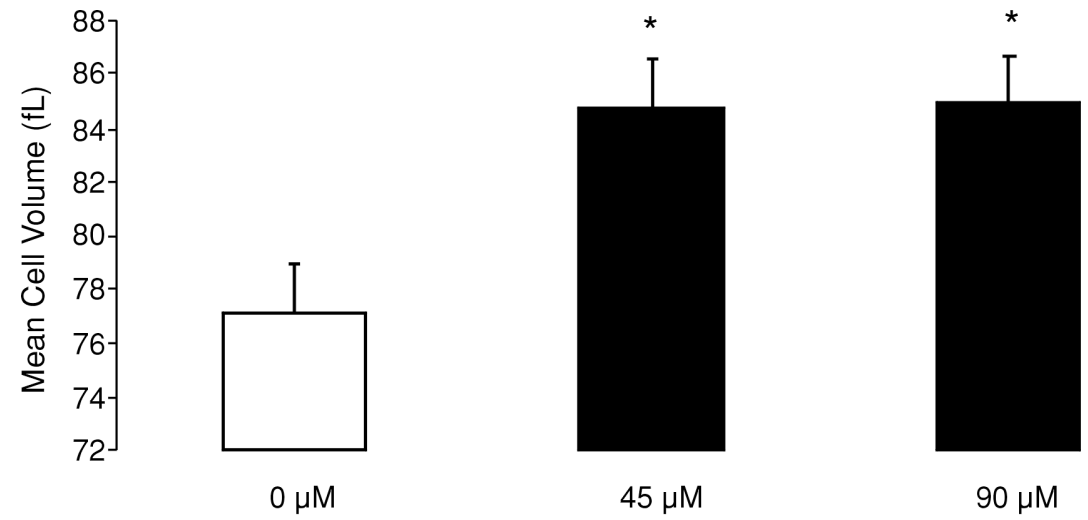

Ciprofloxacin

$90 \mu \mathrm{M}$

Figure 4. Effect of Ciprofloxacin on mean cell volume of erythrocytes (fL) Arithmetic means \pm SEM $(n=10)$ of the erythrocytes exposed for 48 hours to ringer solution without (white bar) or with (black bars) 45-90 $\mu \mathrm{M}$ ciprofloxacin. Y-axis bars show the standard error mean $(\mathrm{SEM}) . *(\mathrm{p}<0.05)$ indicate very significant difference from the absence of ciprofloxacin (ANOVA) 


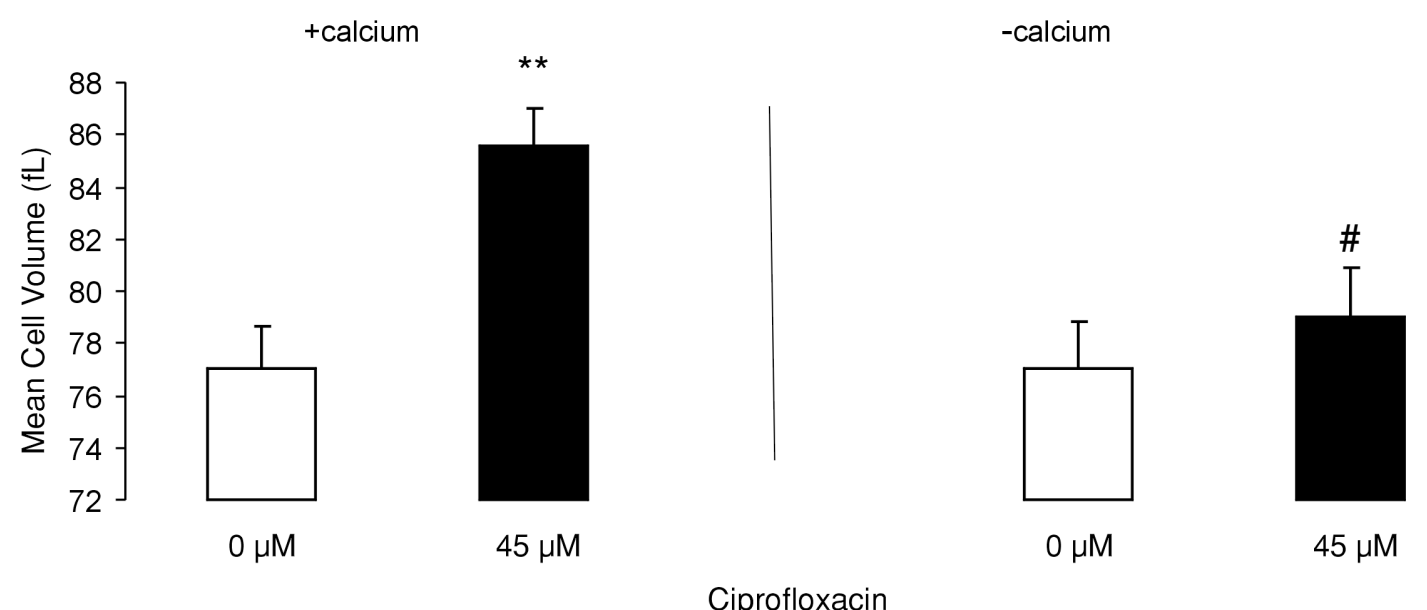

Figure 5. Cell size measurement of Ciprofloxacin exposed erythrocytes in the presence and absence of calcium. Arithmetic means \pm SEM $(\mathrm{n}=10)$ of the erythrocytes exposed for 48 hours to Ringer solution without (white bar) or with (black bars) $45 \mu \mathrm{M}$ ciprofloxacin. $* *$ ( $<<$ $0.01)$ showed the significant effect of erythrocytes size measurement activity between $0-45 \mu \mathrm{M}$ ciprofloxacin treated erythrocytes. \# $(\mathrm{p}<$ 0.05 ) indicates a significant difference from the respective values in the presence of calcium. (ANOVA)
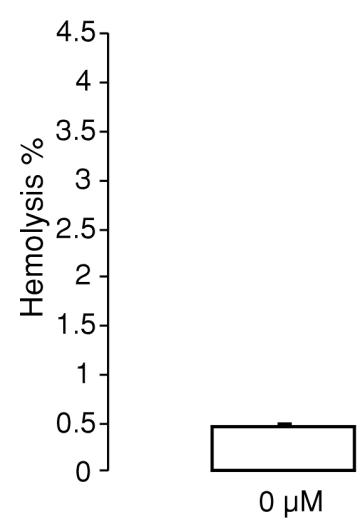

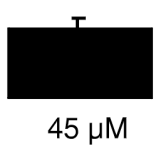

Ciprofloxacin

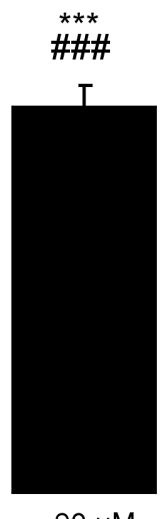

$90 \mu \mathrm{M}$

Figure $6 . \%$ of Ciprofloxacin induced hemolysis in erythrocytes. Arithmetic means \pm SEM $(n=12)$ of the erythrocytes exposed for 48 hours to Ringer solution without (white bar) or with (black bars) 45-90 $\mu \mathrm{M}$ ciprofloxacin. Y-axis bars show the standard error mean (SEM). ***.\#\#\#(p < 0.0001) indicate extremely significant difference from the absence of ciprofloxacin and between $45 \& 90 \mu \mathrm{M}$ respectively (ANOVA)

significant decrease in blebbing effect was noticed in the cells treated with ciprofloxacin in the absence of calcium as compared to the cells exposed to the drug in the presence of calcium. Membrane blebbing is an outcome of the activation of calciumdependent cysteine endopeptidase calpain, which is responsible for the degradation of the erythrocyte's cytoskeleton (30). By removing intracellular and extracellular $\mathrm{Ca}^{+2}$, similar effects could be observed in previous studies $(31,32)$.

Disposing of defective erythrocytes before hemolysis is an important physiological role of eryptosis (33). Hemoglobin is released through hemolyzed erythrocytes that may be filtered through kidneys or precipitate in the acidic lumen of renal tubules (34). Figure 6 is illustrating a highly significant increase of hemolysis percentage after 48-hour exposure of erythrocytes to ciprofloxacin at $90 \mu \mathrm{M}$. A small but non-significant increase in hemolysis \% was also observed at $45 \mu \mathrm{M}$. During hemolysis, the release of erythrocytes contents especially hemoglobin cause reduction in the NO bioavailability that may promote vasomotor instability, systemic vasoconstriction and endothelial dysfunction and con- 
tribute to serious clinical conditions including high blood pressure, pulmonary issues, cardiovascular problems, renal dysfunction, inflammation, thrombosis and increased susceptibility to infection (35). High ROS production was also noticed during the episode of hemolysis (36).

From the results of our study, it is concluded that the used therapeutical doses $(45-90 \mu \mathrm{M})$ of ciprofloxacin may enhance the rate of erythrocytes removal from the circulation through eryptosis and hemolysis due to the induction of oxidative stress and subsequent calcium influx.

\section{Conflict of interest}

The authors declare no conflicts of interest.

\section{REFERENCES}

1. Ghosh S., Qi R., Carter K.A., Zhang G., Pfeifer B.A. et al.: Biochem. Eng. J. 141, 43 (2019).

2. Meyerhoff A., Albrecht R., Meyer J.M., Dionne P., Higgins K. et al.: Clin. Infect. Dis. 39, 303 (2004).

3. Heemskerk C.P., Woldman E., Pereboom M., van der Hoeven R., Mantel-Teeuwisse A. et al.: J. Pharm. Pharm. Sci. 20, 360 (2017).

4. Zargar Baboldashti N., Poulsen R.C., Franklin S.L., Thompson M.S., Hulley P.A.: Am. J. S. Med. 39, 1929 (2011).

5. Lang K., Duranton C., Poehlmann H., Myssina S., Bauer C. et al.: Cell Death Differ. 10, 249 (2003).

6. Shaik N., Lupescu A., Lang F.: Cell. Physiol. Biochem. 30, 512 (2012).

7. Lang F., Lang K.S., Lang P.A., Huber S.M., Wieder T.: Antioxid. Redox Signal. 8, 1183 (2006).

8. Brugnara C., de Franceschi L., Alper S.L.: J. Clin. Invest. 92, 520 (1993).

9. Berg C., Engels I., Rothbart A., Lauber K., Renz A. et al.: Cell Death Differ. 8, 1197 (2001).

10. Jilani K., Lang F.: Toxins 5, 703 (2013).

11. Lang F., Gulbins E., Lerche H., Huber S.M., Kempe D.S. et al.: Cell. Physiol. Biochem. 22, 373 (2008).

12. Lang F., Jilani K., Lang E.: Expert Opin. Ther. Targets. 19, 1219 (2015).
13. Pastor M.C., Sierra C., Doladé M., Navarro E., Brandi N. et al.: Clin. Chem. 44, 924 (1998).

14. Lupescu A., Bissinger R., Jilani K., Lang F.:Toxins 6, 1559 (2014).

15. Li P., Cheng N.N., Chen B.Y., Wang Y.M.: Acta. Pharmacol. Sin. 25, 1262 (2004).

16. Martins-Duarte E.S., Dubar F., Lawton P., da Silva C.F., Soeiro Mde N. et al.: PLoS One 10, 0125705 (2015).

17. Giannopolitis C.N., Ries S.K.: Plant Physiol. 59, 315 (1977).

18. Ullah S., Li Z., Hasan Z., Khan S.U., Fahad S.: Ecotoxicol. Environ. Safety 161, 270 (2018).

19. d'Onofrio G., Chirillo R., Zini G., Caenaro G., Tommasi M. et al.: Blood 85, 818 (1995).

20. Khushboo P., Jadhav V., Kadam V., Sathe N.: Pharmacogn. Rev. 4, 69 (2010).

21. Bissinger R., Malik A., Jilani K., Lang F.: Basic Clin. Pharmacol. Toxicol. 115, 396 (2014).

22. Kayser F., Novak J.: Am. J. Med. 82, 33 (1987).

23. Abraham S., Soundararajan C., Vivekanandhan S., Behari M.: Indian J. Med. Res. 121, 111 (2005).

24. Tokarz P., Kaarniranta K., Blasiak J.: Biogerontology 14, 461 (2013).

25. Stohs S.J., Bagchi D.: Free Radic. Biol. Med. 18, 321 (1995).

26. Vijayaraghavan R., Paneerselvam C.: Int. J. Appl. Biol. Pharm. Tech. 2, 409 (2011).

27. Mladenov M., Gokik M., Hadzi-Petrushev N., Gjorgoski I., Jankulovski N.: Physiol. Res. 64, 891 (2015).

28. Buettner G.R., Schafer F.Q.: Teratology 62, 234 (2000).

29. Hassan M., Hadi R., Al-Rawi Z., Padron V., Stohs S.: J. Appl. Toxicol. 21, 69 (2001).

30. Bratosin D., Estaquier J., Petit F., Arnoult D., Quatannens B. et al.: Cell Death Differ. 8, 1143 (2011).

31. Malik A., Bissinger R., Liu G., Liu G., Lang F.: Toxins 7, 1396 (2015).

32. Huber S.M., Gamper N., Lang F.: Pflügers Archiv. 441, 551 (2001).

33. Charras G.T., Coughlin M., Mitchison T.J., Mahadevan L.: Biophys. J. 94, 1836 (2008).

34. Lang E., Qadri S.M., Lang F.: Int. J. Biochem. Cell Biol. 44, 1236 (2012).

35. Rapido F.: Blood Transfus. 15, 218 (2017).

36. Prousek J.: Pure Appl. Chem. 79, 13 (2007).

Received: 23.06 .2019 